1 Pottipati A, Dave PB, Gumaste V, Vieux U. Tuberculous abscess of the liver in acquired immunodeficiency syndrome. $\mathcal{F}$ Clin Gastroenterol 1991;13:549-53.

2 Lupatkin H, Brau N, Flomenberg P, Simberkoff MS. Tuberculous abscesses in patients with AIDS. Clin Infect Dis 1992;14:1040-4.

3 Radin R. Intraabdominal Mycobacterium tuberculosis versus Mycobacterium avium intracellulare infections in patients with AIDS: distinction based on CT findings. AfR 1991;156: AIDS: dist

4 Anon. Case records of the Massachusetts General Hospital: Case 3. N Engl f Med 1995;4:249-56.

5 Benson CA. Disease due to the Mycobacterium avium comBenson CA. Disease due to the Mycobacterium avium com-
plex in patients with AIDS: epidemiology and clinical plex in patients with AIDS: epidemiology and

syndrome. Clin Infect Dis 1994;18(suppl 3):218-22.
6 Klatt EC, Jensen DF, Meyer PR. Pathology of Mycobacte-

6 Klatt EC, Jensen DF, Meyer PR. Pathology of Mycobacteciency syndrome. Hum Pathol 1987;18:709-14.
7 Khalil T, Uzoaru I, Nadimpalli V, Wurtz R. Splenic tuberculous abscess in patients positive for human immunodeficiency virus: report of two cases and review. Clin Infect Dis 1992;14:1265.

8 Massenkeil G, Opravil M, Salfinger M, von Graevenitz A, Lüthy R. Disseminated coinfection with Mycobacterium avium complex and Mycobacterium kansasii in a patient with AIDS and liver abscess. Clin Infect Dis 1992;14:618-9.

9 Horsburgh, CR Jr. Mycobacterium avium complex infection in the acquired immunodeficiency syndrome. $N$ Engl $7 \mathrm{Med}$ 1991;324:1332-8.

10 Inderlied CB, Kemper CA, Bermudez LEM. The Mycobacterium avium complex. Clin Microbiol Rev 1993;6:266-301.

\title{
Abdominal pain in a healthy young man
}

\author{
Michelle N Dizon, Glenn Matfin
}

A 31-year-old man was admitted with a one-day history of dull intermittent abdominal pain. The patient had recently arrived from a vacation in Jamaica. He admitted to nausea, constipation, and loss of appetite but denied vomiting and diarrhoea. The pain was not associate with eating. He denied any fever or chills. On examination, he looked anxious but otherwise well developed and well nourished. The abdomen was soft, non-distended and only slightly tender with deep palpation. He had normal bowel sounds. Routine blood tests were normal. The plain abdominal X-ray is shown in figure 1 .

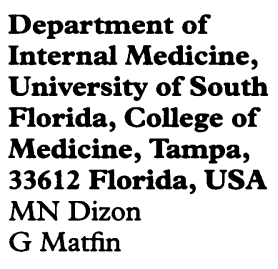

Accepted 20 August 1997

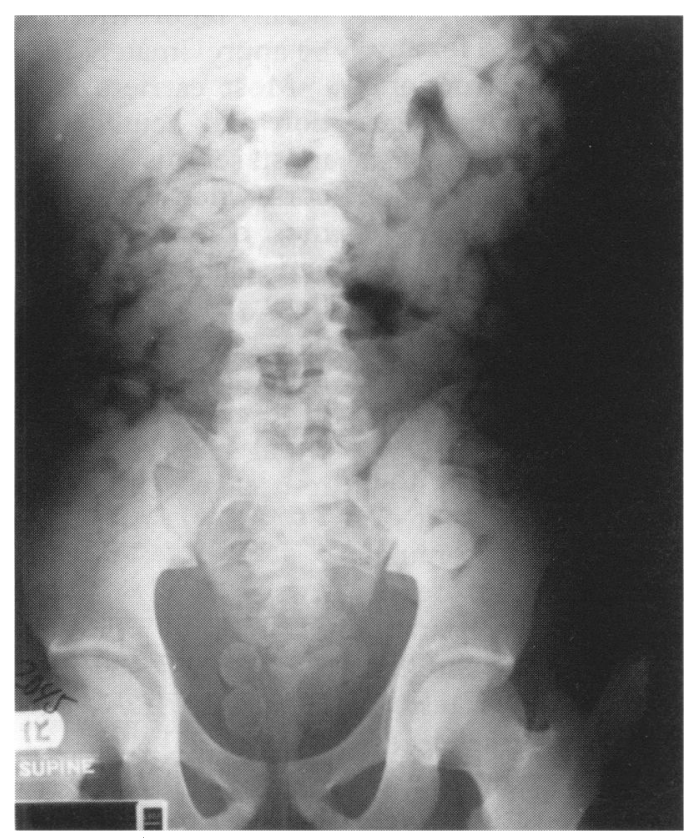

Figure 1 Plain abdominal X-ray

\section{Questions}

1 What does the plain abdominal X-ray in figure 1 show?

2 What is the immediate management of this condition?

3 What other investigations would be helpful? 
Answers

QUESTION 1

The plain X-ray of the abdomen (figure 1) showed round and oval densities throughout the gastrointestinal tract consistent with intracorporeal drug packages seen in international drug traffickers, otherwise known as 'body packers' or 'mules'. Radiological evidence of packages is a consequence of the way the drugs are packaged. The 'double condom sign' is a lucent rim around the packet due to air trapped between the layers of the condoms or latex. Air can be also trapped at the sites of the knots around the tips of the condoms and appear as a rosette shape.

\section{QUESTION 2}

The majority of carriers do not require medical attention. Management is focused on the uneventful passage of the packages with gentle laxatives and oral enemas. Stronger cathartics may actually promote obstruction or rupture of packages. Often, carriers are observed in the intensive care units for signs of cocaine intoxication until all packages have been passed. This is confirmed by two packet-free stools and negative abdominal films.

Activated charcoal may be used to adsorb cocaine leaking from packets. Whole bowel irrigation with polyethylene glycol may be a relatively safe and effective means of rapid elimination of the packets in an asymptomatic carrier. Surgical intervention is reserved for any clinical evidence of toxicity, bowel obstruction, or radiological evidence of imminent package rupture. Upper gastrointestinal endoscopy has been used for diagnostic and removal purposes. However this technique is not recommended due to the risks of package perforation.

\section{QUESTION 3}

Abdominal plain X-ray is used to establish diagnosis and location, although false negatives have been known to occur. Because of the increasing sophistication of the packaging of drugs, detection of body packing is becoming more difficult, and other methods are being utilised. One study shows a striking relation between the presence of drugs in urine and the presence of drug-filled bundles. ${ }^{1}$ Urine is tested by enzyme immunoassay for the presence of benzoylecgonine, the major metabolite of cocaine. The high incidence of positive urine test results is likely to be secondary to leakage of drug from packets with semipermeable walls, ${ }^{1}$ drug use by the carrier, and contamination of the packets with the powder. A preliminary study showed the efficacy of contrast examination of the bowel with a water-soluble compound for the detection of drug packets where initial abdominal X-rays are negative. ${ }^{1}$ In addition, the water-soluble compounds are osmotically active and accelerate the spontaneous elimination of packages by acting as a purgative.

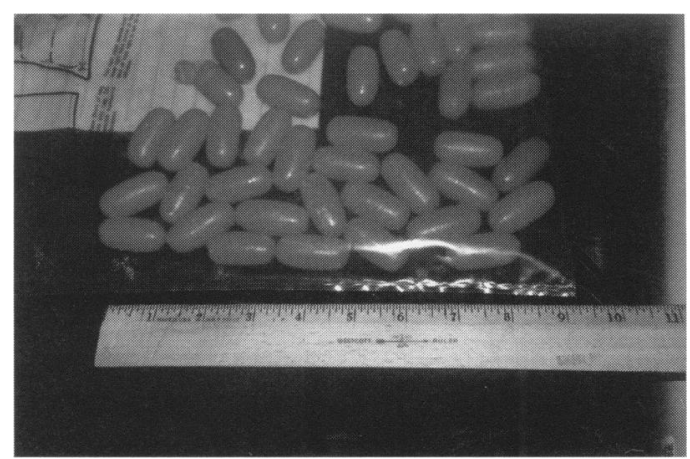

Figure 2 Latex packets each containing $10 \mathrm{~g}$ of cocaine

\section{Discussion}

The first reported cases of cocaine 'body packers' was in $1975 .^{2}$ Since then, there have been many other reports throughout the world reflecting a growing industry. Packages containing heroin or cocaine may be swallowed or inserted into the rectum or vagina to be retrieved after the 'mule' has cleared customs.

Drugs are packaged in layers of cellophane, condoms or latex. They have been reported to contain 1-12 $\mathrm{g}$ of heroin or cocaine, and 'mules' have been trained to swallow up to 200 packets. The patient in this case had swallowed 177 latex packets, each one containing $10 \mathrm{~g}$ of cocaine (figure 2 ). This patient was paid $\$ 4000$ to carry the packets into the US. Officers unofficially report the street value of the packets to be approximately $\$ 100000$.

Most carriers are asymptomatic. Obstruction and acute cocaine intoxication are the most serious complications. Obstruction occurs when the packages become entangled, most commonly in the pylorus, ileocecal valve and splenic flexure. ${ }^{3}$ Cocaine is easily absorbed through all mucous membranes and has a toxic dose of $25 \mathrm{mg}$ with a reputed lethal dose of 500 mg. Should a package rupture, the carrier is exposed to a dosage many times the toxic and lethal level. Cocaine blocks the presynaptic re-uptake of noradrenaline and dopamine,

\section{Summary points}

- most 'body packers' or 'mules' are asymptomatic and management is focused on the passage of drug-filled packages with laxatives, oral enemas, or whole bowel irrigation with polyethylene glycol

- surgical intervention is reserved for signs of cocaine toxicity, bowel obstruction, or radiological evidence of package rupture

- symptoms of acute cocaine toxicity include agitation, tachycardia, palpitations, hypertension, confusion, and hallucinations. Death may occur as a result of arrhythmias, seizures, and metabolic acidosis

- medical management of cocaine toxicity is focused on treating complications (seizures, arrhythmias, hypertension, and sympathomimetic effects) 
leading to an excess of transmitter at postsynaptic receptor sites. Signs and symptoms of acute cocaine intoxication include agitation, tachycardia, palpitations, hypertension, hyperthermia, confusion, disorientation, and hallucinations. Massive doses can result in arrhythmias, seizures, and metabolic acidosis, which is often fatal.

Medical treatment is focused on treating complications as they arise. Propranolol 1 $\mathrm{mg} / \mathrm{min}$ intravenously may specifically antagonise the sympathomimetic effects of cocaine. Diazepam $2.5-5.0 \mathrm{mg}$ or high-dose chlorpro-

1 Gherardi R, Marc B, Alberti X, Baud F, Diamant-Berger O. A cocaine body packer with normal abdominal plain radiograms, value of drug detection in urine and contrast study of the bowel. Am F Forensic Med Pathol 1990;11:154-7.

2 Mebanex C, De Vito J. Cocaine intoxication, a unique case. f Fla Med Assoc 1975;62:19-20. 3 Beck NE, Hale JE. Cocaine 'body packers.' Br $\mathcal{F}$ Surg 1993;
12:1513-6. mazine have been used to prevent seizures. Dantrolene $1 \mathrm{mg} / \mathrm{kg}$ intravenously over $10-15$ min has variable success in treating refractory hyperthermia. Once the patient is stabilised, surgery may be indicated to prevent rupture of any remaining packets.

\section{Final diagnosis}

Intracorporeal cocaine-filled packets in a 'body-packer'

Keywords: cocaine; drug smuggling; body-packer

4 Lancashire MJR, Legg PK, Lowe M, Davidson SM, Ellis $\mathrm{BW}$. Surgical aspects of international drug smuggling. $B M F$ 1988;296:1035-7.

5 Trent MS, Kim U. Cocaine packet ingestion, surgical or medical management? Arch Surg 1987;122:1179-81.

\title{
An 88-year-old woman with tetraparesis after a fall
}

\author{
B Klemenz, P A Banaszkiewicz, F W Smith
}

An 88-year-old woman with a medical history of drug-controlled hypertension and type II diabetes mellitus was admitted to hospital after a fall headlong downstairs at home. She sustained a blow to the right temporal region of her skull, but did not lose consciousness. She was immediately paralysed after her fall. On admission to hospital the patient complained of weakness and an 'odd feeling' in both her arms and legs but denied any neck pain.

On examination she was found to be fully conscious with spontaneous breathing. A minor contusion was present over her right temple. The upper extremities demonstrated grade $3 \mathrm{MRC}$ power with diminished triceps and biceps jerks. A total flaccid paralysis was present in her right leg with grade 3 MRC power in her left leg. No knee or ankle jerks were present in either leg. The left plantar response was down-going, the right equivocal. She had no sensation below shoulder level although joint position sense in the toes was maintained. Peri-anal sensation and rectal tone were preserved It was necessary to insert an indwelling urinary catheter for urinary retention.

Initial treatment consisted of immobilisation in a hard collar. Skull X-rays were taken in the accident and emergency department which were normal. After consultation with the radiology department it was decided to proceed straight to an emergency magnetic resonance imaging (MRI) scan of the cervical spine (figure), rather than perform cervical spine X-rays.

\section{Woodend Hospital, Eday Road, Aberdeen AB15 6LS, UK Department of Geriatric Medicine B Klemenz MRI Centre \\ F W Smith}

Department of Orthopaedic Surgery, University of Aberdeen Medical School, Aberdeen, UK

P A Banaszkiewicz

Correspondence to $\mathrm{B}$ Klemenz, Royal Victoria Hospital of Edinburgh, Department of Care of the Elderly, 13 Craigleith Road, Edinburgh EH4 2DN, UK

Accepted 20 August 1997

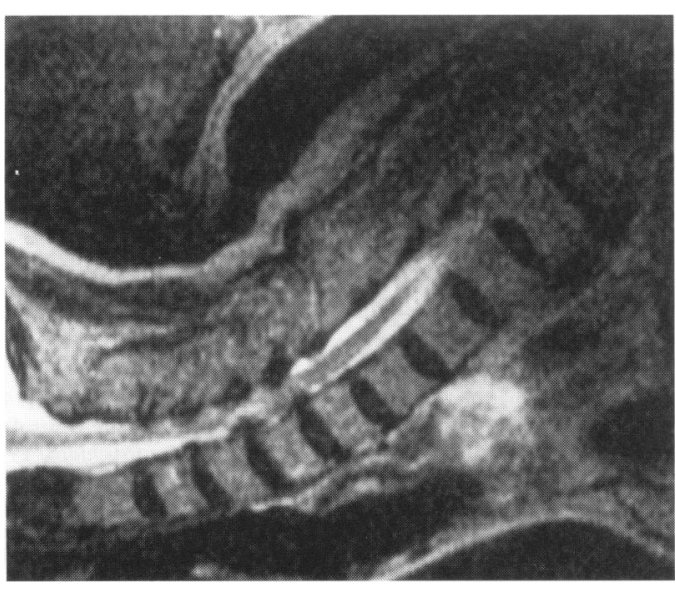

\section{Questions}

1 What is the most probable diagnosis?

2 What does the MRI scan show?

3 What is the treatment of choice in this case? 